\title{
A FORMAÇÃO INICIAL E CONTINUADA DOS TREINADORES PARANAENSES DE TÊNIS
}

\author{
Caio Correa Cortela, Federação Paranaense de Tênis - FPT, Curitiba, Paraná - Brasil \\ Layla Maria Aburachid, Universidade Federal de Mato Grosso - UFMT, Cuiabá, Mato \\ Grosso - Brasil \\ Silvio Pinheiro Souza, Federação Paranaense de Tênis - FPT, Curitiba, Paraná - Brasil \\ Débora Navarro Rocha Cortela, Instituto Federal do Paraná - IFPR, Foz do Iguaçu, Paraná \\ - Brasil \\ Juan Pedro Fuentes, Universidad de Extremadura UEX, Extremadura, Cáceres - Espanha
}

\section{RESUMO}

O presente estudo objetivou conhecer quem são os treinadores paranaenses de tênis, como trilharam o seu caminho até iniciarem a carreira e como se formaram como profissionais. Para coletar essas informações, primeiramente foi construído e validado um questionário especificamente desenhado para essa finalidade. Participaram da amostra 58 treinadores com

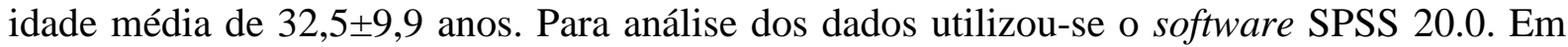
posse dos dados, foi possível verificar que a classe de treinadores paranaenses de tênis, em sua maioria, é composta por homens que iniciaram a carreira por volta dos 19,1 \pm 4 anos de idade, após trabalharem como boleiros. Em geral, esses treinadores apresentam um bom nível técnico estando classificados como $1^{\mathrm{a}}$ ou $2^{\mathrm{a}}$ classes no ranking da FPT. A maior parte relatou estar cursando ou ser formado em Educação Física ou Esporte, demonstrando grande interesse na formação continuada, traduzido pela presença massiva nos cursos de capacitação oferecidos pela CBT e no desejo de participarem de um curso pós-graduação na modalidade. A formação inicial e continuada dos treinadores demonstrou influenciar de forma significativa a renda obtida pelos profissionais, sendo mais determinante do que nível técnico de jogo apresentado.

Palavras-Chave: Formação de treinadores; Treinadores paranaenses; Tênis.

\section{INITIAL ANDCONTINUINGTRAININGOFTENNISCOACHESIN PARANA STATE}

\begin{abstract}
This study aimed to know who the Parana state tennis coaches are, how they made their way until they began their careers and they turned into professionals. In order to collect this information, at first a survey was made and validated, and it was made specifically for this purpose. Took part in this sample 58 coaches with average age $32,5 \pm 9,9$ years old. For the data analyses was used the software SPSS 20.0. Having access to this data, it was possible to verify that the class of the Parana State tennis coaches, mostly, is composed of men who began their careers around the age 19,1 \pm 4 years old, after having worked catching the balls. In general, these coaches show a good technical level being classified as $1^{\text {st }}$ or $2^{\text {nd }}$ classes in the ranking of FPT. The most reported to be attending or have been majored in Physical
\end{abstract}


Education Major, shown a great interest in the continuing training, provided by the massive presence in training courses offered by CBT and wishing to take part in the postgraduate courses in the sport. The initial and continuing training of the trainers has shown to be influencing in a significant way the income these professionals earn, being more decisive than the game technical level that was shown.

Key-Words: Coaches training; Parana state coaches; Tennis

\section{FORMACIÓN INICIAL Y CONTINUA DE LOS ENTRENADORES PARANAENSES DE TENIS}

\section{RESUMEN}

El presente estudio tuvo como objetivo conocer quiénes son los entrenadores paranaenses de tenis, como trillaron su camino para iniciar su carrera y cómo se formaron profesionales. Para recopilar esta información, primeramente se construyó y validó un cuestionario diseñado específicamente para este propósito. Participaron una muestra de 58 entrenadores con una edad promedia de 32,5 \pm 9,9 años. Para el análisis de los datos se utilizó el software SPSS 20.0. Luego de recolectar los datos, fue posible verificar que la clase de los entrenadores paranaenses de tenis, en su mayoría, es compuesta por hombres que comenzaron sus carreras alrededor de los 19,1 \pm 4 años de edad, después de trabajar como recogepelotas. Generalmente, estos entrenadores tienen un buen nivel técnico y están clasificados como $1^{\mathrm{a}} \mathrm{o}$ $2^{\text {a }}$ clases en el ranking de la FPT. La mayor parte informó que está cursando o es formado en Educación Física o Deporte, mostrando gran interés en la formación continua, traducido por la presencia masiva en los cursos de capacitación ofrecidos por la CBT y con el deseo de participar de un curso de postgrado en la modalidad. La formación inicial y permanente de los entrenadores de mostró influir de manera significativa los ingresos obtenidos por los profesionales, siendo más determinante que el nivel técnico del juego presentado.

Palabras-Clave: Formación de entrenadores; Entrenadores paranaenses; Tenis. 


\section{INTRODUÇÃO}

Nos últimos anos o crescimento e o papel desempenhado pelo esporte tem sido tema de diversos debates na literatura. ${ }^{1}$ De acordo com Pimentel et al., ${ }^{2}$ o esporte tem assumido o status de fenômeno globalizador, sendo responsável por uma parcela significativa das movimentações financeiras mundiais e atuando como pano de fundo para distintas manifestações políticas e de poder. Nessa direção, Marques $^{3}$ relata que, ultimamente, o esporte é bem mais do que um divertimento, constituindo-se em uma indústria, um polarizador de múltiplas atividades profissionais, um estilo de vida, uma cultura. A representatividade do esporte no cenário internacional é tão pronunciada que, atualmente, existem mais países filiados ao Comitê Olímpico Internacional do que à Organização das Nações Unidas. ${ }^{4}$

A busca pela prática esportiva remete a objetivos distintos, dando ao esporte um significado plural e com diferentes sentidos. Apesar do grande apelo do esporte de rendimento junto à mídia, Gaya e Torres $^{5}$ e Gaya ${ }^{6}$ destacam que os motivos que levam as pessoas a praticarem esporte não se restringem apenas a essa vertente. Observam-se quatro grandes dimensões onde os praticantes se enquadram: o esporte de alto rendimento, ou excelência; esporte escolar ou como meio educacional; esporte de lazer ou de participação; e esporte e saúde ou de reabilitação e reeducação.

Nesse contexto, a profissão de treinador aparece como uma carreira emergente. $\mathrm{O}$ oficio que inicialmente era desempenhado por voluntários, ou restrito como profissão ao esporte de alto rendimento, teve de se adequar às novas expectativas dos praticantes a fim de contemplar todas as dimensões do esporte e atender à crescente demanda pela prática esportiva. ${ }^{3}$

Apesar de afirmar que o status do treinador ainda se encontra bastante associado à antiga imagem deste indivíduo enquanto atleta, Marques $^{3}$ destaca que as competências necessárias para exercer plenamente essa profissão parecem transcender o simples conhecimento de aspectos técnicos e táticos aprendidos durante os anos de prática de uma determinada modalidade. De acordo com Nunes, ${ }^{7}$ para desempenhar de forma eficaz a função de treinador é preciso ter não só a qualificação e formação específica da modalidade, mas outros aspectos 
fundamentais para o exercício da profissão, tais como conhecimentos sobre biologia, fisiologia, metodologia do treinamento, pedagogia, psicologia, organização e administração. Cientes da importância do treinador para o desenvolvimento do esporte, da necessidade de um maior número de estudos nessa área para melhorar a formação desses profissionais, como relatado por Ramos et al., ${ }^{8}$ e da escassez de estudos documentada por Gomes et al. ${ }^{1}$ e Rufino e Dario, ${ }^{9}$ pretendeu-se com este trabalho conhecer quem são os treinadores paranaenses de tênis, como trilharam o seu caminho até iniciarem a carreira e como se formaram como profissionais.

\section{METODOLOGIA}

\section{Amostra}

A seleção da amostra ocorreu por conveniência. De uma população inicial de 180 treinadores estimada junto aos 40 clubes filiados à Federação Paranaense de Tênis (FPT), foram escolhidos, por terem participado das reuniões técnicas realizadas pela FPT no primeiro semestre de 2012, 65 treinadores. Em virtude de falhas no preenchimento, sete questionários foram retirados da amostra totalizando para a análise dos dados 58 professores. Para efeito de análise, o grupo de treinadores denominado de Capital $(n=37)$ foi composto exclusivamente pelos treinadores de Curitiba, enquanto o grupo Interior $(n=21)$ constitui-se de treinadores de Arapongas, Londrina, Imbituva, Marechal Candido Rondon, Maringá e Ponta Grossa.

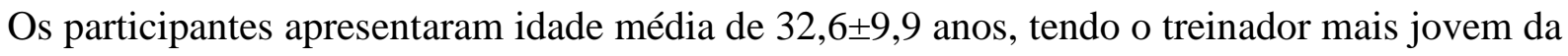
amostra 19 anos e o mais velho 63 anos de idade.

\section{Recolha dos dados e instrumento de coleta}

Para a recolha dos dados foi aplicado um questionário desmembrado em três seções: a primeira voltada para a formação inicial e continuada dos professores de tênis; a segunda buscava informações sobre o mercado de trabalho; e uma terceira voltada ao levantamento da visão dos sujeitos quanto à atuação da FPT no desenvolvimento do tênis no Paraná.As coletas de dados foram realizadas presencialmente nas reuniões da FPT ocorridas no primeiro semestre de 2012. 
A escolha por este instrumento (questionário com questões semiestruturadas, sem identificação) resultou da ponderação entre as vantagens e desvantagens dessa técnica de coleta em relação a outras técnicas de pesquisa descritiva como a entrevista, por exemplo. De acordo com Thomas, Nelson e Silverman ${ }^{10}$ a utilização do questionário se justifica quando se tem como necessidade obter respostas, com frequência e em uma ampla área geográfica. Tendo em vista o teor pessoal de algumas questões presentes no instrumento, o anonimato favorece a sinceridade nas respostas.

Para elaboração do instrumento de coleta criou-se uma equipe de investigação composta por cinco colaboradores de distintas áreas, na qual se inclui os investigadores. Os membros dessa equipe apresentam formação inicial e percursos profissionais distintos, com o intuito de atender às particularidades possivelmente apresentadas pelos treinadores, sujeitos da pesquisa. Após quatro reuniões de estudos e discussões sobre os critérios para elaboração do instrumento, estabeleceu-se um questionário base a ser submetido à análise piloto para sua validação. Para o processo de validação foram utilizadas as recomendações propostas por Arias e Fernández ${ }^{11}$ (adaptado de Robson); por Hoinville e Jowell citados por Cohen e Manion, ${ }^{12}$ e por Manzano e González. ${ }^{13}$ Nesse sentido, os treinadores que participaram da coleta piloto utilizaram uma tabela de verificação e validação do conteúdo de 15 itens, onde foram avaliados: a estrutura, a terminologia e o tempo médio de preenchimento do instrumento. Esses mesmos critérios foram utilizados por Fuentes e Villar ${ }^{14}$ em um estudo considerado como referência nesta linha de investigação.

Participaram do projeto piloto de validação do questionário base 10 treinadores que tinham, no mínimo, cinco anos de experiência profissional. Após preencherem a tabela de verificação e validação do conteúdo, obteve-se uma média 4,32 $\pm 0,68$, em uma escala de likert que variava de 1 (completamente em desacordo) e 5 (totalmente de acordo), o que demonstra uma avaliação positiva dos treinadores com relação ao instrumento. Nenhum dos itens avaliados apresentou valor inferior a três nessa escala. O tempo médio despendido para preenchimento do questionário foi de $16,1 \pm 4,3$ minutos.

Conhecidos os resultados e acatando as sugestões relevantes apresentadas pelos treinadores, procedeu-se, em comum acordo com os membros da equipe de investigação, a versão três do instrumento, que foi aplicada aos treinadores paranaenses.

Conexões: revista da Faculdade de Educação Física da UNICAMP, Campinas, v. 11, n. 2, p. 60-84, abr./jun. 2013. ISSN: 1983-9030 


\section{Análise de dados}

Para análise estatística dos dados, utilizou-se o software SPSS 20.0. Foram realizadas estatísticas descritivas de tendência central e dispersão e cálculos de frequências e percentagens para as variáveis observadas. Após a aplicação do teste Kolmogorov-Smirnov com $\mathrm{p} \leq 0,05$, verificou-se que a amostra não apresentou uma distribuição normal. Dessa forma, optou-se pela utilização do teste não paramétrico Mann-Whitney, com o nível de significância estabelecido em $\mathrm{p} \leq 0,05$ para a comparação entre os dados apresentados pelos treinadores dos grupos Capital e Interior.

Por fim, para verificar o grau de associação entre as variáveis: tempo de carreira, carga horária, renda mensal, experiência como jogador, escolaridade e a formação continuada, foi utilizado o coeficiente de correlação de Sperman.

\section{ANÁLISE E DISCUSSÃO DOS DADOS}

\section{Caracterização da amostra e formação inicial e continuada dos treinadores paranaenses de} tênis

A idade de início de carreira apresentada pelos treinadores paranaenses de tênis encontra-se em conformidade com as idades sugeridas por Fuentes e Villar ${ }^{14}$ para treinadores espanhóis de tênis e por Gomes et al. ${ }^{1}$ em diversas modalidades. De um modo geral, observa-se que esses treinadores iniciaram cedo na profissão, uma vez que, mais da metade já atuava no mercado antes dos 18 anos e que aproximadamente $80 \%$ iniciaram a carreira antes de completarem 20 anos de idade (TABELA 1).

Tabela 1 - Caracterização da amostra expressa em anos

\begin{tabular}{|c|c|c|c|c|c|c|c|c|c|}
\hline & \multicolumn{2}{|c|}{ Amostra total } & \multicolumn{3}{|c|}{ Capital } & \multicolumn{3}{|c|}{ Interior } & \multirow{2}{*}{$\mathbf{p}$} \\
\hline & $\square$ & $\sigma$ & Md & $\square$ & $\boldsymbol{\sigma}$ & Md & $\square$ & $\sigma$ & \\
\hline Idade & 32,6 & 9,9 & 31 & 33,4 & 9,1 & 29 & 31,2 & 10,9 & 0,237 \\
\hline $\begin{array}{l}\text { Idade de início da } \\
\text { carreira }\end{array}$ & 19,1 & 4 & 18 & 19,8 & 5 & 17 & 18 & 2,6 & 0,734 \\
\hline Tempo de carreira & 13,5 & 9,9 & 11 & 13,7 & 9,4 & 10 & 13,2 & 11 & 0,149 \\
\hline
\end{tabular}

Segundo Coelho e Silva et al., ${ }^{15}$ se levarmos em consideração as responsabilidades que o treinador é obrigado a assumir, essa idade pode ser considerada precoce, uma vez que além 
dos aspectos didáticos pedagógicos inerentes ao ensino do esporte, a função de treinador requer, entre outras atividades: a estruturação das sessões de treino, o planejamento a longo prazo da carreira esportiva, o acompanhamento técnico em viagens para eventos. Isso demanda organização e responsabilidade do profissional, competências não muito comuns entre os jovens.

Ressalta-se, no entanto, que esse panorama deverá ser alterado gradativamente nos próximos anos. Até pouco tempo atrás, não se exigia do treinador qualquer tipo de formação específica para a atuação no mercado de trabalho. Com a regulamentação do profissional de Educação Física e Esporte, através da Lei Federal $\mathrm{n}^{\circ}$ 9.696/98, os interessados em atuar como treinadores de tênis deverão, necessariamente, cursar a faculdade de Educação Física ou Esporte, o que levará os mesmos a ingressem no mercado de trabalho com, no mínimo, 21 anos.

A verificação de que mais da metade dos treinadores inquiridos já se encontravam no mercado de trabalho há 10 anos ou mais, ressalta a experiência apresentada pela amostra em questão. De acordo com Abraham et al., ${ }^{16}$ o período de 10 anos de atividade profissional é considerado como referência para a obtenção da expertise nessa profissão.

Esses dados revelam ainda que boa parte dos treinadores paranaenses ingressou na nessa carreira em um período marcante para o tênis nacional, a chamada Era Guga. Vale lembrar que entre os anos 1997 e 2004 o Brasil viveu momentos memoráveis com grandes conquistas individuais e participações significativas na Davis Cup, considerada a maior competição por equipes da modalidade.

Como observado na Tabela 1, não foram encontradas diferenças estatisticamente significativas entre os grupos Capital e Interior para as variáveis relacionadas à idade do treinador, para a idade de início de carreira e para o tempo de carreira.

Assim como observado pelos estudos ${ }^{1,14-15,17}$ com diferentes modalidades esportivas, constatase no presente trabalho que a profissão de treinador de tênis é exercida, em sua grande maioria, por profissionais do sexo masculino (GRÁFICO 1). 


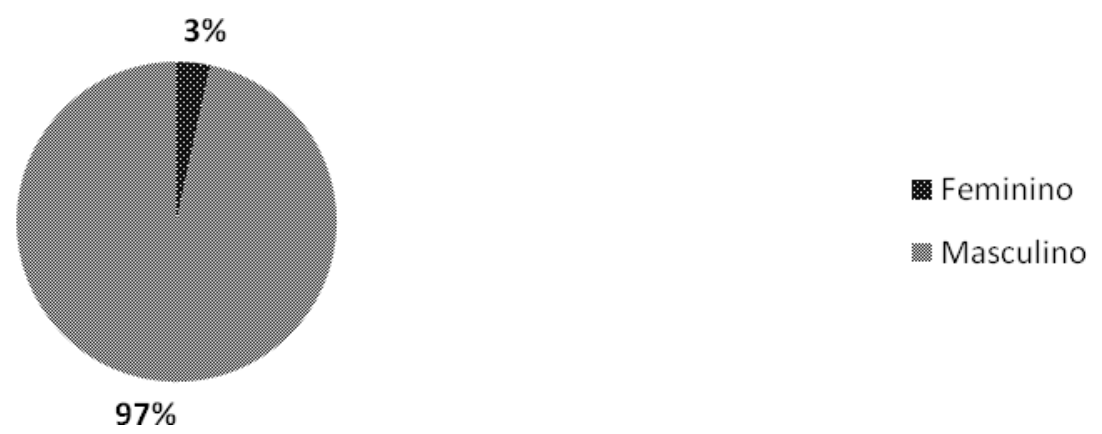

Gráfico 1: Gênero dos treinadores da amostra.

Além das explicações socioculturais entre os sexos citadas por Resende et al., ${ }^{17}$ no caso concreto do tênis paranaense, a pequena participação das mulheres na prática federada pode ser apontada com um dos fatores que contribuem para esse cenário.

Apesar de o tênis, conjuntamente com o golfe, ter sido uma das primeiras modalidades esportivas a contarem com a participação feminina nas olimpíadas e do grande destaque dado pela mídia às atletas dessa modalidade, verifica-se que a presença feminina no tênis brasileiro e, de forma mais específica no Paraná, ainda é reduzida se comparada aos tenistas do sexo masculino.

Tomando como exemplo as duas últimas edições dos Campeonatos Paranaenses InfantoJuvenil e de Classes, dois dos mais importantes eventos do calendário de competições da FPT, observa-se que de um total de 455 inscrições apenas 88 (19\%) foram efetuadas por atletas do sexo feminino. Em um cenário como esse, é difícil acreditar que em um curto espaço de tempo haverá um incremento significativo no número de candidatas a treinadoras de tênis

No que diz respeito à experiência demonstrada pelos treinadores enquanto atletas, verificou-se que os mesmos apresentam nível técnico elevado, uma vez que mais da metade desses relataram estar inseridos em uma das três principais opções de resposta, a saber: atleta com pontuação nos rankings da Men's Professional Tennis (ATP) ou Women's Tennis Association (WTA); atletas Top 10 do ranking nacional adulto, ou tenistas classificados como primeira classe do sistema estadual de classificação (GRÁFICO 2). 

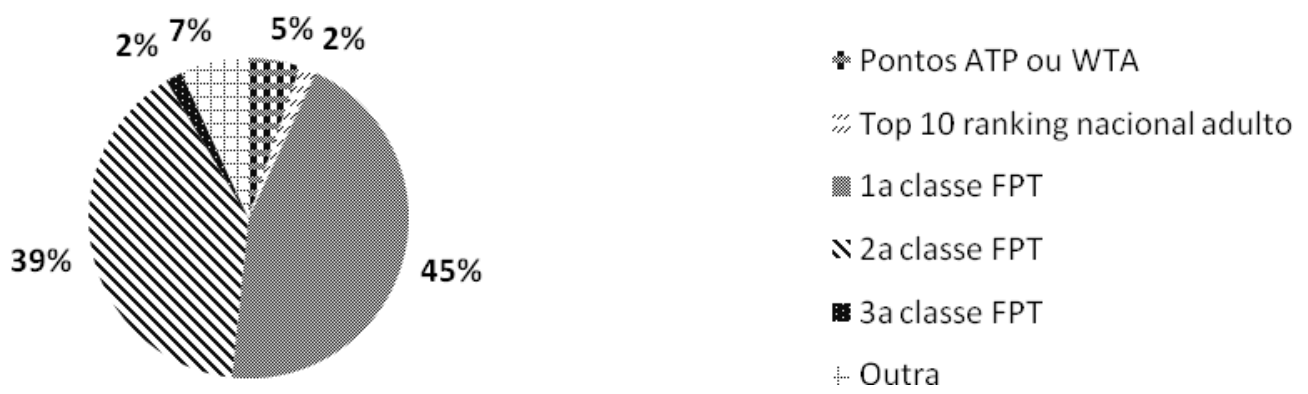

Gráfico 2: Experiência como tenista.

A necessidade de um elevado nível técnico para se ensinar a modalidade tem sua raiz associada aos diferentes papéis desempenhados pelo treinador ao longo da história do tênis. Por muitas décadas, o nível técnico apresentado pelo treinador foi considerado como sinônimo da capacidade do mesmo de ensinar, delimitando também com quais níveis de atletas ele poderia trabalhar.

Vale lembrar que do início da modalidade até os anos 40 do século XX, o tênis foi ensinado como uma atividade puramente técnica. Nessas condições, acreditava-se que o profissional responsável pelo seu ensino deveria ser um exímio jogador, para que o mesmo pudesse demonstrar os gestos técnicos com perfeição e, assim, propiciar ao aluno um ótimo modelo a ser reproduzido. ${ }^{18}$

Entre os anos 50 e 80 do século XX a importância dos aspectos técnicos continuaram a crescer, dando à metodologia analítica de ensino um papel preponderante nas aulas. Nessa perspectiva, esperava-se que o treinador fosse não só um excelente jogador, mas que também dominasse completamente as distintas fases que compunham os gestos técnicos do tênis, já que todos os tenistas deveriam passar por todas essas fases. ${ }^{18}$

Atualmente os programas de iniciação esportiva para o tênis encontram-se pautados nos pressupostos apresentados pelas metodologias contemporâneas de ensino dos jogos esportivos, como o Teaching Games for Understanding (TGFU) e o Sport Education Model (SE). Com um enfoque baseado no jogo, em situações de jogos reduzidos e contextualizados, e na utilização de materiais adaptados, essas metodologias destacam a necessidade de se priorizar, inicialmente, os aspectos táticos do jogo, enfatizando o ensino dos gestos técnicos 
somente após a compreensão, por parte do aluno, do papel desempenhado pela técnica como ferramenta para solucionar os problemas encontrados no jogo. Nessa visão, o treinador deixa de ser o centralizador do conhecimento e passa a ser responsável pela apresentação de tarefas que desafiem os alunos, realizando ainda intervenções que possibilitem os debates e a construção do conhecimento. ${ }^{19}$

Apesar de as metodologias de ensino terem mudado consideravelmente nas duas últimas décadas, no Brasil verifica-se que o ensino do tênis ainda encontra-se associado às metodologias tradicionais como a analítica. ${ }^{20-22}$ Dessa forma, não é de se estranhar a baixa percentagem de treinadores classificados como terceira classe, ou inferior a essa, no sistema estadual de classificação.

Por fim, dois treinadores relataram estar classificados como quarta classe da FPT. Esses resultados acendem o debate quanto à necessidade de níveis elevados de desempenho para se atuar como treinador. Em algumas vertentes do esporte, como o tênis de alto rendimento, o histórico de treinador como ex-atleta demonstra ter um papel determinante no exercício da profissão. $^{14}$

Nesse patamar, pesa em favor desses treinadores não só seu nível técnico, mas também todo seu conhecimento do circuito profissional, vivenciado durante os anos de carreira como jogador. Assim, os contatos pessoais com os promotores de eventos e os árbitros; o prestígio junto à federação local; o conhecimento dos locais de competição, por exemplo, podem facilitar a obtenção de convites e demais oportunidades de crescimento de carreira para o tenista, contribuindo ainda para a redução nos custos inerentes à carreira de atleta profissional. ${ }^{14}$ Por outro lado, questiona-se até que ponto essa experiência como ex-atleta pode interferir positivamente em sua atividade profissional nas demais vertentes do esporte, traduzindo-se em uma melhoria na qualidade do ensino oferecida ao aluno.

Diferentemente de outras modalidades esportivas como o basquetebol ou voleibol, por exemplo, onde boa parte dos treinadores iniciou a carreira como ex-jogador ou após cursar a faculdade de Educação Física ou Esporte como citado por Coelho e Silva et al. ${ }^{15}$ e Resende et al.; ${ }^{17}$ a maioria dos profissionais que atuam como treinadores de tênis no Paraná iniciaram suas atividades na modalidade como pegadores de bolas. (GRÁFICO 3). 


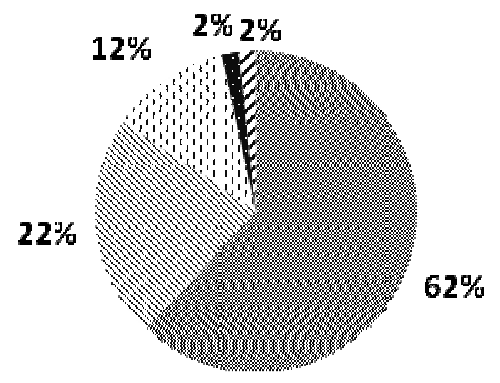

- Pegador de bolas

w $[x$-jogador

ii. Após cursar Zd. Fisica ou Esporte

- Preparador Físico

\%.utro

Gráfico 3: Início da carreira como treinador.

Assim como no golfe, onde até hoje a figura do caddy (que a pessoa responsável por carregar os equipamentos do jogador) é tradicional, no tênis brasileiro, por muitos anos, o pegador de bolas, também conhecido como boleiro esteve presente, auxiliando nas aulas e durante as partidas.

Por décadas o ensino do tênis baseou-se na repetição exaustiva dos gestos técnicos encontrados no jogo. ${ }^{18}$ Nesse contexto, o suporte oferecido pelos boleiros dinamizava as aulas permitindo ao treinador que as bolas não acabassem durante os exercícios, possibilitando a utilização continua de drills em situação fechada de ensino das habilidades motoras ao longo de toda a aula.

Com a mudança de foco do ensino do tênis para uma metodologia baseada nos aspectos táticos e na ênfase ao ensino aberto das habilidades motoras, evidenciou-se que a função desempenhada pelos pegadores de bolas estava mais associada ao comodismo dos jogadores do que à necessidade dessa função para decorrer o jogo, colocando em xeque esse ofício.

Essa situação preocupa, uma vez que o trabalho como boleiro foi apontado como o principal caminho trilhado pelos treinadores antes de iniciarem concretamente a carreira de treinador, o que leva a crer que, em médio prazo, poderá haver um impacto direto na oferta de treinadores aptos a atuarem com a modalidade no Estado do Paraná.

Além desse fator, pesa ainda o fato de o tênis ser considerado um esporte de elite no país. ${ }^{23}$ Essa situação pode ser ilustrada pelo estudo conduzido por Cortela et al. ${ }^{24}$ com tenistas paranaenses da categoria infantil, onde se verificou que todos os tenistas participantes da 
amostra estavam enquadrados nas classes socioeconômicas A1, A2 e B1, consideradas as de maior poder aquisitivo na classificação da Associação Brasileira de Empresas de Pesquisa, da qual fazem parte apenas nove por cento da população nacional.

Em virtude do acima exposto, é comum verificar que os tenistas que têm contato com a modalidade por um longo período e que apresentam níveis satisfatórios de jogo, ao não serem capazes de seguir atuando profissionalmente como atletas, optam por seguirem profissões mais tradicionais e com maior remuneração, o que também contribui negativamente para a formação de novos profissionais para área.

Um único indivíduo revelou ter iniciado sua trajetória como treinador diferente das descritas no Gráfico 3, destacando que era o responsável por supervisionar os pegadores de bolas, a marcação de horários das quadras e os torneios internos realizados no clube em que trabalhava.

Relativamente ao nível máximo de escolaridade apresentado pelos treinadores, verifica-se atualmente uma mudança na perspectiva de formação, observando-se um aumento na procura e no número de treinadores com formação em nível superior específica (GRÁFICO 4).
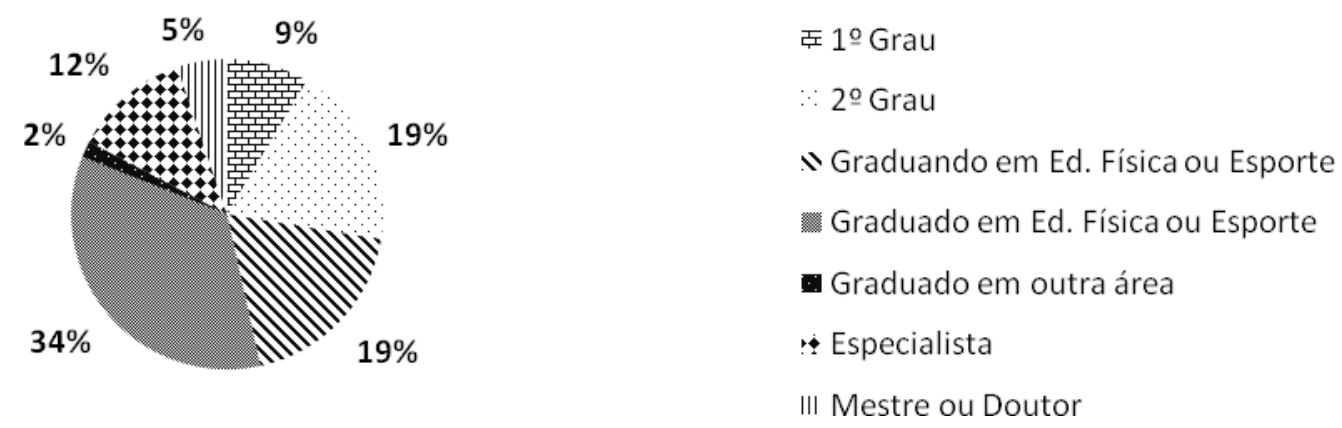

Gráfico 4: Nível de escolaridade dos treinadores paranaenses de tênis.

Com a aprovação da Lei ${ }^{\circ}$ 9.696/98, que regulamenta a atuação do profissional de Educação Física e Esporte, os profissionais que não comprovaram o exercício da profissão anteriormente à vigência dessa lei necessariamente terão de ser graduados na área para poderem atuar no mercado de trabalho. Como era de se esperar, essa imposição tem promovido a melhoria da educação formal apresentada pelos treinadores, fato comprovado 
pela observação da formação inicial relatada pelos profissionais que já atuavam anteriormente à aprovação da lei e a dos treinadores que iniciaram na carreira após o período de vigência da mesma.

Enquanto $56 \%$ dos profissionais que se encontravam no mercado de trabalho anteriormente a entrada em vigor dessa lei declararam possuir como nível máximo de formação, o ensino fundamental ou médio ( $1^{\circ}$ ou $2^{\circ}$ grau), apenas $6 \%$ dos demais treinadores apresentaram esse tipo de formação, constando-se que $30 \%$ desses indivíduos cursavam Educação Física ou Esporte e $64 \%$ eram graduados, especialistas ou possuíam também mestrado ou doutorado nessa área.

O início da carreira do treinador também demonstrou ser um fator determinante para o nível de formação, apontando para a influência exercida pelos aspectos socioeconômicos. Enquanto $85 \%$ dos treinadores que iniciaram a carreira após pararem de jogar apresentavam formação em nível superior, eram especialistas ou possuíam mestrado ou doutorado, apenas $31 \%$ dos treinadores que começaram como boleiros percorreram caminhos similares. Nessa mesma direção, verificou-se que nenhum ex-jogador possuía apenas o primeiro ou segundo graus como nível máximo de escolaridade, contrastando com o valor de $44 \%$ apresentado pelos treinadores, que começaram a carreira como pegadores de bola.

Apesar de a maior parte dos treinadores (55\%) estarem cursando ou já serem graduados em Educação Física ou Esporte, terem relatado o contato com a disciplina Tênis de Campo como matéria eletiva ou como disciplina da grade curricular ao longo do curso, essa não é a realidade vivenciada em todo o país.

De acordo com Dias et al., ${ }^{25}$ poucas universidades oferecem a disciplina Tênis de Campo em seu currículo. Segundo os autores, os principais motivos alegados por essas instituições para não ofertarem a disciplina foram por considerarem o esporte elitista, pela falta de materiais e quadras específicas e pela ausência de currículo e de profissionais capacitados para atuarem com a modalidade.

Tendo em vista, que as novas metodologias de ensino não requerem a utilização de materiais e quadras oficiais para a iniciação esportiva a essa modalidade, a falta de profissionais Conexões: revista da Faculdade de Educação Física da UNICAMP, Campinas, v. 11, n. 2, p. 60-84, abr./jun. 2013. 72 ISSN: $1983-9030$ 
capacitados para atuarem com o tênis e especificamente com o tênis ambiente escolar parece ser o maiores desafios para a popularização do esporte no país. ${ }^{19}$

Esse quadro, associado à redução no número de boleiros, suscita a necessidade de a FPT repensar suas ações em prol do desenvolvimento do tênis estadual, ofertando às diversas instituições de ensino superior do Estado suporte técnico, através de cursos de curta duração e de formação que permitam aos acadêmicos conhecerem as possibilidades de ação dentro da modalidade e os requisitos necessários para atuarem com o tênis, tanto em ambiente escolar quanto no mercado convencional de trabalho.

Cursos de aperfeiçoamento e de pós-graduação lato sensu seriam outras possibilidades para dar continuidade ao processo formal de educação dos treinadores, uma vez que $71 \%$ da amostra demonstrou interesse em participar de um curso de especialização à distância.

No Brasil, algumas universidades lançaram o curso de pós-graduação em Tênis de Campocomo o Cesumar de Maringá, a faculdade de Assis Gurgacz de Cascavel e a ESEF de Jundiaí. Desses, apenas a ESEF conseguiu preencher as vagas necessária para que o curso pudesse acontecer.

Alguns pontos ainda parecem pesar para que seja difícil a formação de turmas nesse tipo de curso no país. O primeiro é que anteriormente a Lei $n{ }^{\circ} 9.696 / 98$, uma parcela representativa dos treinadores não possuía graduação na área, o que inviabilizava a participação em um curso acadêmico de especialização, fato que deverá ser modificado em breve devido à obrigatoriedade da graduação para o exercício da profissão de treinador de tênis.

Outro ponto determinante diz respeito ao perfil das formações procuradas pelos treinadores. Assim como relatado por Sanz et al., ${ }^{26}$ verifica-se que a formação dos treinadores paranaense de tênis está fortemente associada ao sistema confederativo. Nesse sentido, seria fundamental para o sucesso dos cursos de especialização nessa área associarem-se à CBT ou às Federações locais para que, além do diploma universitário, houvesse paralelamente um diploma federativo que comprovasse a participação no curso e que aumentasse o reconhecimento social do treinador que atingisse essa etapa de sua formação. 
Além desses, verifica-se que os cursos de pós-graduação em Educação Física ou Esporte ocorrem, geralmente, divididos em blocos, comprometendo ao longo do ano, um número significativo de finais de semanas. De acordo com Fuentes e Villar, ${ }^{14}$ o comprometimento dos finais de semana impede a participação dos treinadores nos cursos de formação, uma vez que os mesmos alegam trabalhar nesse período, supervisionando os atletas em competições.

No caso concreto dos treinadores paranaenses, observa-se um comportamento semelhante ao descrito anteriormente para os treinadores espanhóis. Dessa forma, a necessidade de trabalhar aos finais de semana pode ser o fator determinante para a não participação nesse tipo de formação, tendo em vista que os mesmos relataram trabalhar regularmente com acompanhamento técnico, organização de eventos e clínicas de tênis. Uma vez que essas atividades acontecem prioritariamente aos finais de semana no calendário da FPT, a participação em um curso presencial de especialização poderia afetar consideravelmente o orçamento desses treinadores, tornando-se um empecilho.

Nesse cenário, as opções pelos cursos à distância ou semipresenciais surgem como alternativas viáveis para que os treinadores possam seguir se capacitando através da via universitária. Pelo segundo ano consecutivo, a Espanha realizará o mestrado acadêmico em tênis. A primeira edição ocorreu na Universidade Aberta de Valência. Para 2013 o curso ocorrerá na Universidade Camilo José Cela, em Madrid, em uma ação conjunta com a RFET e International Tennis Federation (ITF). O curso que conta com momentos práticos de estágio supervisionado nas grandes academias de tênis espanholas tem atraído treinadores de vários países, inclusive do Brasil.

A via universitária não é a única opção para a formação dos treinadores. De um modo geral, a qualificação desses profissionais ocorre por três vias distintas: as federativas (ITF, confederação nacional ou pelas federações ou associações estaduais); a universitária; e as formações obtidas através das associações privadas como a United States Professional Tennis Association (USPTA), United States Professional Tennis Registry (USPTR), Professional Tennis Registry (PTR), Registro Profesional de Tenis (RPT), entre outras. ${ }^{26}$

De acordo com Gomes et al., ${ }^{1}$ a formação acadêmica apresentada pelos treinadores interfere na escolha dos mesmos em relação às vias e às entidades responsáveis pela formação Conexões: revista da Faculdade de Educação Física da UNICAMP, Campinas, v. 11, n. 2, p. 60-84, abr./jun. 2013. ISSN: $1983-9030$ 
continuada. Nessa direção, verifica-se que os treinadores com formação até o ensino médio atribuem às federações a responsabilidade sobre as ações de capacitação, enquanto os treinadores com formação superior em Educação Física ou Esporte consideram que todas as entidades oficialmente reconhecidas deveriam exercer essa função. ${ }^{1}$

Assim como descrito por Sanz et al. ${ }^{26}$ e por Resende et al., ${ }^{17}$ verifica-se no presente estudo que a formação dos treinadores paranaenses está fortemente associada à via confederativa, uma vez que $85 \%$ dos treinadores relatou haver participado de algum curso de capacitação por essa via nos últimos cinco anos. Tomando como base os resultados apresentados por Fuentes e Villar ${ }^{14}$ e Mendes, ${ }^{27}$ com treinadores espanhóis e portugueses respectivamente, observa-se uma maior adesão dos treinadores paranaenses para esse tipo de formação.

É de se destacar ainda a frequência com que os treinadores paranaenses participam dessas formações, tendo em vista que aproximadamente metade desses profissionais realizaram quatro cursos, ou mais, nos últimos anos, como pode ser averiguado nos dados sistematizados nessa pesquisa (GRÁFICO 5).

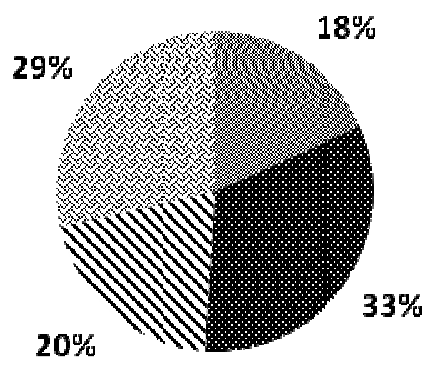

- Apenas una participaçäo

De duas a três participaçōes ミ゙ De quatro a cinco participaçöes 染 Mais de cinco

Gráfico 5: Frequência de participações em cursos.

Relativamente às titulações expedidas nesse âmbito, Fuentes e Villar ${ }^{14}$ relatam que as mesmas encontram-se divididas em três ou quatro módulos, sendo que as cargas horárias, os prérequisitos e os conteúdos de cada módulo variam de um país para outro. Apesar dessas diferenças, observa-se entre as nações consolidadas na modalidade como Alemanha, Espanha e França, por exemplo, que existe a obrigatoriedade de se cumprir, pelo menos, 300 horas de formação específica para se obter a maior titulação federativa. ${ }^{14,28}$

Na França e Grã-Bretanha o sistema federativo encontra-se associado à via universitária. Dessa forma, para se atingir o mais alto patamar como treinador na França, é necessário Conexões: revista da Faculdade de Educação Física da UNICAMP, Campinas, v. 11, n. 2, p. 60-84, abr./jun. 2013. ISSN: 1983-9030 
desenvolver uma dissertação de mestrado relacionada à modalidade, enquanto na GrãBretanha exige-se dos treinadores a participação no Curso de Coaching universitário com mais 900 horas de capacitação. ${ }^{14,28}$

O Brasil ainda se apresenta como uma nação em desenvolvimento na modalidade. Segundo Sanz et al. $^{26}$ essas nações costumam optar pelo modelo de formação de treinadores estabelecido pela ITF. Atualmente esse modelo é constituído de três níveis: um primeiro destinado à iniciação, o segundo direcionado aos tenistas avançados e o último dedicado ao alto rendimento.

Para facilitar a realização dos cursos no país, o Departamento de Capacitação de Professores da CBT optou pela divisão dos dois primeiros níveis em sete módulos, totalizando 175 horas de formação específica. Em virtude de o último módulo (módulo $G$ ) ter sido lançado após o período de coletas desse estudo, serão considerados para análise apenas os módulos de $A \mathrm{a} F$.

Como observado no Gráfico 6, verifica-se que os módulos $A \mathrm{a} C$ são os cursos com maior número de participações entre os treinadores. A opção por esses cursos demonstra estar associada ao perfil técnico dos alunos que fazem aulas ou treinamentos com esses profissionais. De um modo geral, os treinadores relataram trabalhar com um maior número de alunos em fase de iniciação ou aperfeiçoamento, destacando-se o aperfeiçoamento de tenistas adultos como a categoria de maior representatividade.

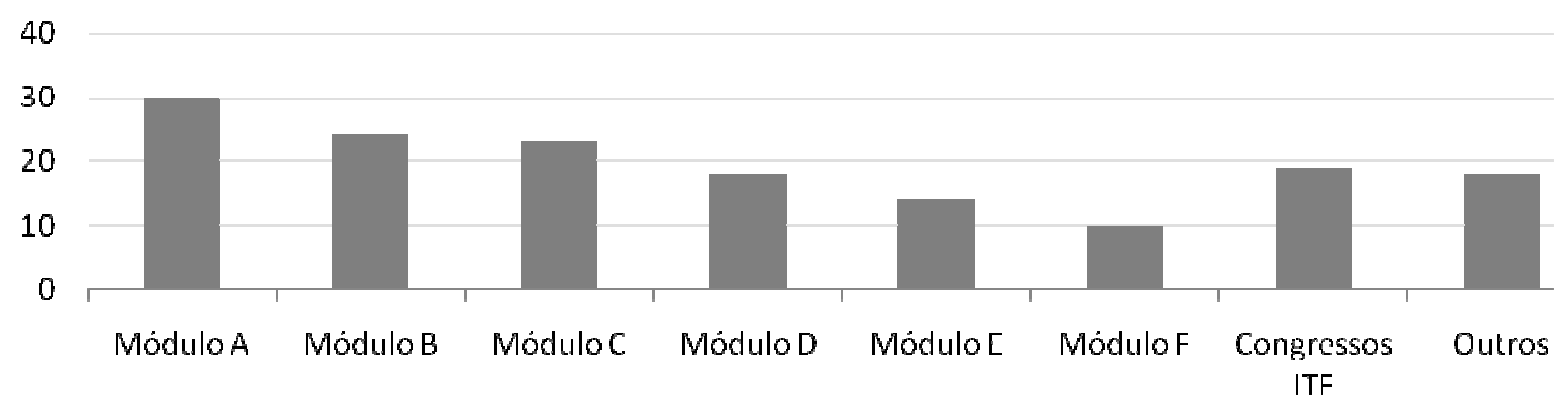

Gráfico 6: Perfil dos cursos de formação frequentados pelos treinadores (em valores absolutos).

Nesse contexto o módulo $A$ de caráter introdutório a profissão, apresenta como principais conteúdos o papel a ser desempenhado pelo treinador enquanto profissional da área e os pré- 
requisitos necessários para a iniciação esportiva ao tênis. Em um segundo momento o módulo $B$ introduz os treinadores nas aulas individuais, apresentando os diferentes tipos de lançamentos de bolas e efeitos, destacando-se ainda as técnicas de correções. Por fim, o módulo $C$ destaca a organização das aulas em grupo e o trabalho das cinco situações de jogo: sacar, devolver, jogo de fundo, jogo de rede e o jogo de passador. ${ }^{29}$

À medida que o nível se torna mais elevado (módulos $D, E$ e $F$ ) constata-se um decréscimo na frequência de participação. Nesse cenário verifica-se que os congressos da ITF e outras opções de cursos superam esses módulos em valores absolutos. O curso mais frequentado pelos treinadores como outras opções de formação foi o Clube Junior, seguido dos cursos de gestão esportiva, Play and Staye da USPTR, com frequências iguais de participações.

A procura por outras opções de cursos aponta para um nicho ainda aberto no mercado brasileiro.

Diferentemente de outras nações como Estados Unidos e Espanha, por exemplo, no país não existem associações privadas nem federações promovendo paralelamente à CBT outras opções de formação. Esse fato realça a necessidade da FPT, como instituição responsável pelo desenvolvimento do tênis estadual, de promover ao menos ações pontuais como workshops, seminários e congressos para a melhoria da capacitação dos profissionais que trabalham com a modalidade no Paraná.

A realização desses eventos apresenta-se ainda como uma excelente oportunidade para aproximar a FPT das instituições de ensino superior e fomentar a iniciação científica sobre a modalidade, tendo em vista que as publicações específicas da área, de um modo geral, apresentam-se baseadas puramente no empirismo dos treinadores de sucesso, como afirma Mendes. $^{27}$

Entre as disciplinas que os treinadores gostariam que aparecesse com maior frequência nos cursos de formação, o Treinamento Técnico/Tático foi a que recebeu maior valorização. Esses resultados vão ao encontro dos apresentados por Fuentes e Villar $^{14}$ e Resende et al., ${ }^{17}$ enfatizando a procura por informações específicas por parte dos treinadores (TABELA 2). 
Os treinadores do interior demonstraram maior interesse na presença das disciplinas Periodização do Treinamento e Propaganda e Marketing. A maior importância dada por esses treinadores à disciplina de Propaganda e Marketing pode estar associada ao menor número de promotoras de eventos e de clubes de grande porte nessas regiões.

Tabela 2 - Participação das disciplinas no currículo dos cursos de formação de treinadores

\begin{tabular}{|c|c|c|c|c|c|c|c|c|c|}
\hline \multirow[t]{3}{*}{$\begin{array}{l}\text { Ausente do } \\
\text { currículo } \\
1\end{array}$} & $\begin{array}{l}\text { Pouca } \\
\text { articipação no } \\
\text { currículo } \\
2\end{array}$ & \multicolumn{3}{|c|}{$\begin{array}{c}\text { Participação regular } \\
\text { no currículo } \\
3\end{array}$} & \multicolumn{3}{|c|}{$\begin{array}{c}\text { Muita participação no } \\
\text { currículo } \\
4\end{array}$} & \multicolumn{2}{|c|}{$\begin{array}{l}\text { Muitíssima } \\
\text { participação no } \\
\text { currículo } \\
5\end{array}$} \\
\hline & \multicolumn{2}{|c|}{ Amostra total } & \multicolumn{2}{|c|}{ Capital } & \multicolumn{4}{|c|}{ Interior } & \multirow{2}{*}{$\mathbf{P}$} \\
\hline & $\square$ & $\sigma$ & Md & $\square$ & $\boldsymbol{\sigma}$ & Md & $\square$ & $\sigma$ & \\
\hline Pedagogia do esporte & 3,8 & 1 & 4 & 3,7 & 1 & 4 & 4 & 0,8 & 0,250 \\
\hline $\begin{array}{l}\text { Treinamento } \\
\text { Técnico/Tático }\end{array}$ & 4,5 & 0,7 & 4,5 & 4,4 & 0,6 & 5 & 4,6 & 0,7 & 0,298 \\
\hline Nutrição esportiva & 3,7 & 1 & 3 & 3,6 & 0,9 & 4 & 3,9 & 1,2 & 0,116 \\
\hline Psicologia do esporte & 4,3 & 0,8 & 4 & 4,2 & 0,9 & 4 & 4,3 & 0,8 & 0,865 \\
\hline $\begin{array}{l}\text { Treinamento das } \\
\text { capacidades motoras }\end{array}$ & 4,3 & 0,9 & 5 & 4,3 & 0,9 & 5 & 4,5 & 0,8 & 0,391 \\
\hline $\begin{array}{l}\text { Periodização do } \\
\text { treinamento }\end{array}$ & 4 & 1 & 4 & 3,9 & 0,8 & 5 & 4,2 & 1,1 & $0,024^{*}$ \\
\hline Traumatologia do tênis & 3,4 & 1,1 & 3 & 3,3 & 1 & 4 & 3,6 & 1,4 & 0,278 \\
\hline Biomecânica & 4,3 & 0,8 & 4 & 4,2 & 0,8 & 5 & 4,4 & 0,9 & 0,262 \\
\hline $\begin{array}{l}\text { Organização e gestão } \\
\text { esportiva }\end{array}$ & 3,7 & 1 & 4 & 3,6 & 1 & 4 & 3,8 & 1,1 & 0,525 \\
\hline Propaganda e marketing & 3,5 & 1 & 3 & 3,3 & 1 & 4 & 4 & 0,9 & $0,016^{*}$ \\
\hline
\end{tabular}

Na Tabela 3 é possível observar o papel exercido pela formação inicial e continuada no que diz respeito à renda apresentada pelos treinadores paranaenses. As moderadas correlações encontradas entre o nível de escolaridade e a participação em cursos demonstraram exercer maior influência na renda mensal obtida pelos treinadores do que a experiência apresentada pelos mesmos como ex-atletas. Esses dados sugerem que os treinadores que desejarem elevar a suas remunerações deverão investir continuamente em sua capacitação profissional.

Esses resultados reforçam a afirmação de Marques, ${ }^{3}$ que diz que apesar de o histórico como ex-atleta estar associado à imagem do treinador, nem sempre essa experiência se traduz em competência profissional. Tal comportamento fez com que alguns países, como a Austrália, por exemplo, desenvolvessem planos de transição de carreira de atletas para jogadores, bem como de atletas e treinadores para o desempenho de outras funções relacionadas ao esporte. ${ }^{15}$ A experiência apresentada pelos treinadores, traduzida pelo tempo de carreira na área, também demonstrou influenciar significativamente a renda relatada por esses profissionais. Conexões: revista da Faculdade de Educação Física da UNICAMP, Campinas, v. 11, n. 2, p. 60-84, abr./jun. 2013. ISSN: 1983-9030 
Nesse sentido, verifica-se que os treinadores com maior tempo de atuação tendem a ser mais bem remunerados do que os seus pares com menor tempo de carreira.

Por fim, na Tabela 3 o nível de escolaridade e a participação em cursos apresentaram-se moderadamente correlacionados $(\mathrm{r}=+0,37)$, indicando que os treinadores com maior nível de escolaridade tendem a participar com maior frequência dos cursos e congressos relacionados ao tênis.

Tabela 3 - Correlação bivariada simples entre o tempo de carreira, carga horária de trabalho semanal, renda mensal, experiência como jogador, escolaridade e participação nos cursos

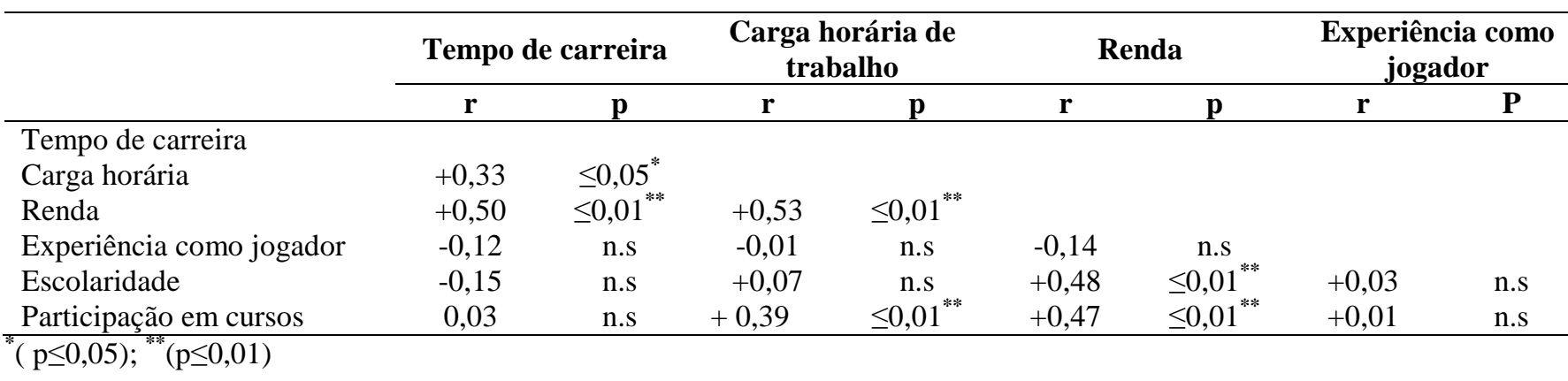

\section{CONSIDERAÇÕES FINAIS}

A análise dos dados permitiu responder as questões propostas para esse trabalho, que foram: Quem são os treinadores paranaenses de tênis? Como trilharam o seu caminho até se tornarem treinadores? Como se formaram como treinadores?

De um modo geral o perfil do profissional que trabalha com tênis no Estado se compõe,

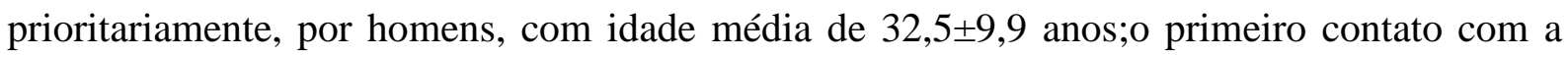
modalidade ocorreu através da prestação de serviços como boleiros nas aulas e torneios; por volta dos 19,1 \pm 4 anos de idade esses indivíduos deram início às atividades como treinadores; como experiência enquanto ex-atletas, a maior parte deles relatou estarem classificados como $1^{\mathrm{a}}$ ou $2^{\mathrm{a}}$ classe no ranking da FPT.

A formação desses profissionais foi diretamente afetada pela criação da lei 9.696/98 que regulamenta a atuação do profissional de Educação Física e Esporte no país. Anteriormente a ela, mais da metade dos treinadores declararam possuir como nível máximo de formação, o ensino fundamental ou médio. Após a promulgação da mesma, verificou-se uma melhora na Conexões: revista da Faculdade de Educação Física da UNICAMP, Campinas, v. 11, n. 2, p. 60-84, abr./jun. 2013. ISSN: 1983-9030 
qualidade da formação, tendo em vista que a maior parte dos treinadores após esse período declarou ser graduado ou estar cursando o ensino superior na área.

Os treinadores relataram haver participado ativamente de atividades de formação continuada, verificando-se que aproximadamente metade desses profissionais esteve presente em quatro ou mais cursos nos últimos cinco anos. O perfil dos cursos realizados é de cunho confederativo, sendo os módulos A, B e C da CBT os mais procurados. Dentre as informações mais relevantes para eles, os conhecimentos mais específicos como o treinamento técnico/tático, o treinamento das capacidades motoras e psicológicas e os conhecimentos da biomecânica aplicada à modalidade são os temas que despertam maior interesse.

A formação inicial e continuada traduzidas pelo nível de escolaridade máximo e pelo número de participações nos cursos de capacitação demonstrou afetar de forma significativa a renda obtida pelos treinadores, apresentando-se como um fator mais determinante que o nível de jogo apresentado.

\section{Considerações para as ações futuras de desenvolvimento da carreira de treinador de tênis no Estado}

Tendo em vista todo o quadro descrito anteriormente sobre a formação inicial e continuada dos treinadores paranaenses de tênis, algumas considerações podem ser úteis para a elaboração de novas ações em prol do desenvolvimento da carreira de treinador de tênis:

1. Os treinadores são peças fundamentais para o desenvolvimento da modalidade no Estado. Nesse sentido, após constatar-se que a grande maioria teve os seus primeiros contatos com a modalidade trabalhando com boleiros e que esse ofício tende a diminuir consideravelmente nos próximos anos, seria fundamental que a FPT propiciasse as instituições de ensino superior, cursos de curta duração (aproximadamente 10h) para que os acadêmicos possam ter contato com a modalidade, conhecendo os requisitos necessários para atuar e o amplo mercado de trabalho;

2. A grande percentagem de treinadores, graduados ou graduandos, associados ao interesse pela abertura de um curso de especialização em tênis e pela enorme procura por atividades de capacitação alertam para um nicho ainda aberto no mercado de trabalho. Dessa forma, o estabelecimento de parcerias com 
instituições de ensino superior, com associações internacionais especializadas na formação de treinadores e com profissionais de renome, mesmo que em atividades pontuais, poderiam dar aos treinadores do Estado outras possibilidades de capacitação.

\section{REFERÊNCIAS}

${ }^{1}$ GOMES, R. E. et al. Acesso à carreira de treinador e reconhecimento das entidades responsáveis pela formação: um estudo com treinadores portugueses em função do nível de escolaridade e da experiência profissional. Revista da Educação Física, Maringá, v. 22, n. 2, p. 185-195, 2011.

${ }^{2}$ PIMENTEL, R. M.; GALATTI, L. R.; PAES, R. R. Pedagogia do esporte e iniciação esportiva tardia: perspectivas a partida da modalidade basquetebol. Pensar a Prática, Goiânia, v.13, n.1, p 1-15, jan./abr. 2010.

${ }^{3}$ MARQUES, A. T. As profissões do corpo: treinador. Treinamento desportivo, Curitiba, v. 5, n.1, p. 4-8, jun. 2000.

${ }^{4}$ PAES, R. R.; BALBINO, H. F. A pedagogia do esporte e os jogos coletivos. In: DE ROSE, D. et al. Esporte e atividade física na infância e adolescência: uma abordagem multidisciplinar. Porto Alegre: Artmed, 2009. p. 73-83.

${ }^{5}$ GAYA, A.; TORRES, L. O esporte na infância e adolescência: alguns pontos polêmicos. In: GAYA, A.; MARQUES, A.; TANI, G. Desporto para crianças e jovens, razões e finalidades. Porto Alegre. Ed. da UFRGS, 2004. p. 57-74.

${ }^{6}$ GAYA, A. Corpos esportivos: O esporte como campo de investigação científica. In: TANI, G.; BENTO, J. O.; PETERSEN, R. D. S. Pedagogia do desporto. Rio de Janeiro. Guanabara Koogan, 2006. p. 101-112.

${ }^{7}$ NUNES, M. A formação e o treinador de futebol. Revista Horizonte, v. 68, p.75-78, 1995. 
${ }^{8}$ RAMOS, V. et al. A aprendizagem profissional - as representações de treinadores desportivo de jovens: quatro estudos de caso. Motriz, Rio Claro, v.17, n. 2, p. 280-291, 2011.

${ }^{9}$ RUFINO, L. G. B.; DARIDO, S. C. A produção científica em pedagogia do esporte: análise de alguns periódicos nacionais. Conexões: revista da Faculdade de Educação Física da UNICAMP, Campinas, v. 9, n. 2, p. 110-132, 2011.

${ }^{10}$ THOMAS, J. R.; NELSON, J. K.; SILVERMAN, S. J. Métodos de pesquisa em atividade física. Porto Alegre: Artmed, 2012.

${ }^{11}$ ARIAS, A.; FERNÁNDEZ, B. La encuesta como técnica de investigación social. In: ROJAS, A.; FERNÁNDEZ, J.; PÉREZ, C. (Ed.). Investigar mediante encuestas: fundamentos teóricos y aspectos prácticos. Madrid: Síntesis, 1988. p. 31-49.

${ }^{12}$ COHEN, L.; MANION, L. Métodos de investigación educativa. Madrid: La Muralla, 1990.

${ }^{13}$ MANZANO, V.; GONZÁLEZ, A. Selección del encuestado. In: ROJAS, A.; FERNÁNDEZ, J.; PÉREZ, C. (Ed.). Investigar mediante encuestas: fundamentos teóricos y aspectos prácticos. Madrid: Síntesis, 1998. p. 99-113.

${ }^{14}$ FUENTES, J. P. G.; VILLAR, F. A. El entrenador de tenis de alto rendimiento: un estudio sobre su formación inicial y permanente. Badajoz: APROSUBA, 2004.

${ }^{15}$ COELHO E SILVA, M. J. C.; ROCHA, I. L.; GONÇALVES, C. E. Treinador de jovens e formação de jovens treinadores. In: COELHO E SILVA, M. J. C.; GONÇALVES, C. E.; FIGUEIREDO, A. Desporto de jovens ou jovens no desporto? Coimbra: FCDEF, 2006. p. 183-196.

${ }^{16}$ ABRAHAM, A.; COLLINS, D.; MARTINDALE, R. The coaching schematic: validation through expert coach consensus. Journal of Sport Sciences, London, v. 24, n. 6, p. 549-564, 2006. 
${ }^{17}$ RESENDE, R.; MESQUITA, I.; ROMERO, J. F. Caracterização e representação dos treinadores acerca da formação de treinadores de voleibol em Portugal. EFdeportes, 2007. Disponível em: 〈http://www.efdeportes.com/efd112/formacao-de-treinadores-de-voleibol-em-portugal.htm>. Acesso em: 22 abr. 2012.

${ }^{18}$ CRESPO, M.; MIRANDA, M. A. Evolución de la metodología en la enseñanza del tenis. Educación Física, Chile, v. 255, p.16-21, 2001.

${ }^{19}$ CORTELA, C. C et al. Iniciação esportiva ao tênis de campo: um retrato do programa play and stay à luz da pedagogia do esporte. Conexões: revista da Faculdade de Educação Física da UNICAMP, Campinas, v. 10, n. 2, p. 214-234, 2012.

${ }^{20}$ BALBINOTTI, C. O ensino do tênis de campo: o processo de aprendizagem progressiva. In: TANI, G.; BENTO, J. O.; PETERSEN, R. D. S. Pedagogia do desporto. Rio de Janeiro. Guanabara Koogan, 2006. p. 399-407.

${ }^{21}$ BOLOGNINI, S.; PAES, R. Propostas pedagógicas e o tênis de campo: confronto entre teoria e prática. Motriz, Rio Claro, v.13, n. 2 (supl.1), p. 70, maio/ago. 2007.

${ }^{22}$ VALENTINI, N. et al. Considerações sobre o desenvolvimento e a aprendizagem motora em crianças. In: BALBINOTTI, C. et al. O ensino do tênis: novas perspectivas de aprendizagem. Porto Alegre: Artmed, 2009. p. 29-45.

${ }^{23}$ MUELLER, J.; RODRIGUES, O. A. F. O tênis nas escolas: uma prática apropriada a cultura escolar. In: BALBINOTTI, C. et al. O ensino do tênis: novas perspectivas de aprendizagem. Porto Alegre: Artmed, 2009. p. 61-79.

${ }^{24}$ CORTELA, C. C. et al. A carga de treinamento e competição dos tenistas infantis paranaenses: um estudo comparativo sobre tenistas com diferentes níveis de desempenhos máximos. Revista Eletrônica FAFIT/FACIC, v. 2, n. 1, p. 1-13, 2011. 
${ }^{25}$ DIAS, J. M. et al. O ensino e aprendizagem de tênis nos cursos de Educação Física. In: JORNADA INTERNACIONAL DE TREINAMENTO E ORGANIZAÇÃO DO TÊNIS, 4., Florianópolis, 2002. Anais... Florianópolis: NETEC, 2002. p. 105-107.

${ }^{26}$ SANZ, D. R.; FUENTES, J. P.; VILLAR, F. A. La formación del entrenador de tenis. Investigación en deportes de raqueta: tenis y bádminton. Múrcia: Universidad Católica San Antonio, 2004. p.341-364, 2004.

${ }^{27}$ MENDES, P. C. Planejamento do treino em tenistas juniores em percurso internacional, segundo as perspectivas dos treinadores e dos jogadores. 2005. $118 \mathrm{f}$. Dissertação (Mestrado em Desenvolvimento e Adaptação Motora) - Faculdade de Ciências do Desporto e Educação Física de Coimbra, Coimbra, 2005.

${ }^{28}$ FUENTES; J. P. G. Análisis de la formación y de los planteamientos didácticos del entrenador de tenis de alta competición en España. 2001. 820 f. Tese (Doutorado em Ciências do Desporto) - Faculdade de Ciências do Desporto, Universidade de Extremadura, Cáceres, 2001.

${ }^{29}$ CONFEDERAÇÃO BRASILEIRA DE TÊNIS (CBT). Cursos. Disponível em: 〈http://cbtenis.uol.com.br/site.aspx/curso-professor $>$. Acesso em: 01 jan. 2012. Acesso em: 01 jan. 2012.

Recebido em: 03 maio 2013 Aceito em: 11 jun. 2013

Contato: Caio Correa Cortela caio.tenis@yahoo.com.br 